\title{
Quantifying air quality co-benefits of climate policy across sectors and regions
}

\author{
Toon Vandyck $^{1}$ (D) Kimon Keramidas $^{1}$ - Stéphane Tchung-Ming ${ }^{1} \cdot$ Matthias Weitzel $^{1}$. \\ Rita Van Dingenen ${ }^{2}$
}

Received: 16 May 2019 / Accepted: 24 February 2020 / Published online: 20April2020

(C) The Author(s) 2020

\begin{abstract}
The overlap in sources of greenhouse gas and local air pollutant emissions creates scope for policy measures to limit global warming and improve air quality simultaneously. In a first step, we derive estimates for the air pollution mortality-related component of the social cost of atmospheric release for 6 pollutants and 56 regions in the world. Combining these estimates with emission inventory data highlights that sector contributions to greenhouse gas emissions and air pollution health impacts differ widely across regions. Next, simulations of future emission pathways consistent with the $2{ }^{\circ} \mathrm{C}$ and $1.5{ }^{\circ} \mathrm{C}$ targets illustrate that strengthening climate policy ambition raises the total value of air quality co-benefits despite lower marginal co-benefits per tonne of greenhouse gas emissions abated. Finally, we use results from a multimodel ensemble to quantify and compare the value of health-related ambient air quality cobenefits of climate policy across sectors and regions. On the global level, overall air quality cobenefits range from $\$ 8$ to $\$ 40$ per tonne of greenhouse gases abated in 2030, with median across models and scenarios of $\$ 18 / \mathrm{tCO}_{2} \mathrm{e}$. These results mask strong differentiation across regions and sectors, with median co-benefits from mitigation in the residential and service sectors in India exceeding $\$ 500 / \mathrm{tCO}_{2} \mathrm{e}$. By taking a sector- and region-specific perspective, the results presented here reveal promising channels to improve human health outcomes and to ratchet up greenhouse gas reduction efforts to bridge the gap between countries' pledges and the global targets of the Paris Agreement.
\end{abstract}

Keywords Climate change $\cdot$ Air pollution $\cdot$ Co-benefits $\cdot$ Short-lived climate forcers $\cdot$ Sustainable development $\cdot$ Integrated assessment

This article is part of a Special Issue reporting results from the "Energy Modeling Forum (EMF)-30 Study on ShortLived Climate Forcers (SLCF) and Air Quality" edited by John Weyant, Steven J Smith, and Zbigniew Klimont

Electronic supplementary material The online version of this article (https://doi.org/10.1007/s10584-02002685-7) contains supplementary material, which is available to authorized users.

Toon Vandyck

Toon.Vandyck@ec.europa.eu

1 European Commission, Joint Research Centre, Seville, Spain

2 European Commission, Joint Research Centre, Ispra, Italy 


\section{Introduction: two birds, one stone?}

Climate change and air pollution are two major planetary challenges that are intimately linked because many of the underlying drivers are common. For instance, fossil fuel combustion and meat consumption imply emissions of greenhouse gases as well as air pollutants with detrimental health impacts. In addition, some pollutants contribute to both problems: methane is a greenhouse gas and a precursor for ground-level ozone, while black carbon contributes to global warming and is a component of particulate matter with diameter smaller than $2.5 \mu \mathrm{m}$ $\left(\mathrm{PM}_{2.5}\right.$ ) (Anenberg et al. 2012; West et al. 2012; Van Dingenen et al. 2018a; Harmsen et al. 2019a). Earlier work has shown that climate policy can have substantial co-benefits by reducing premature deaths related to air pollution (West et al. 2013), while recent work illustrates that the co-benefit value can exceed greenhouse gas mitigation costs in the context of the Paris Agreement (Markandya et al. 2018; Vandyck et al. 2018; Rauner et al. 2019). More broadly, the literature (McCollum et al. 2013; von Stechow et al. 2016; IPCC 2018) points out that climate action can serve as strategic entry point to achieve other Sustainable Development Goals.

Here, we aim to reveal opportunities for targeted policy actions that exploit the synergies between climate change and air pollution by disaggregating region-specific data and model results to the sector level. The main contribution of present study is therefore to highlight air quality-climate synergies and trade-offs across sectors and regions based on historical emission inventory data, the global energy system model POLES-JRC and the multi-model ensemble of the Energy Modeling Forum 30 (EMF-30), with the aim of informing policies with an integrated perspective on sustainability. Earlier work includes source attribution studies that link climate forcing or air pollution impacts to specific source sectors and regions (Unger et al. 2010; Muller et al. 2011; Lelieveld et al. 2015; Silva et al. 2016), but quantitative studies of air quality co-benefits of sectoral greenhouse gas mitigation strategies have started to emerge only recently for the US (Zhang et al. 2017; Ou et al. 2018), for China (Peng et al. 2017a) and for Asia and the Pacific (UNEP 2018). This study contributes to that literature by consistently comparing co-benefits across regions and sectors with a global coverage. By studying broad-based economy-wide climate policies, our findings are complementary to the literature that studies co-benefits of specific policy measures at local level, such as electricity generation (Driscoll et al. 2015) or electricity transmission infrastructure investments in China (Peng et al. 2017b). Furthermore, this paper goes beyond the existing multi-model ensemble work (Rao et al. 2016) by disaggregating air quality-related health co-benefits of climate policy to the sectoral level. As a useful side product, we furthermore derive region-specific estimates of the social costs of atmospheric release per tonne of air pollutant emissions based on premature mortality impacts, extending the work of Shindell (2015).

A better understanding of when and where co-benefits are potentially large is relevant for at least four reasons. The first one builds on political economy arguments in that policy measures with near-term and localised (co-)benefits may face lower barriers to acceptability. Second, this information may help prioritise policy actions when aiming to ratchet up emission reductions under the review-and-revise policy cycle introduced by the global stocktake exercise in the Paris Agreement. Third, high co-benefit values may indicate the most relevant areas for policy integration between potentially fragmented government departments of industry, agriculture, energy, climate, air quality and others. Fourth, the timing of co-benefits may have implications for the optimal design of climate policy over time. 
The remainder of the paper is organised as follows. The next section lays out the construction of a $\mathrm{PM}_{2.5}$-equivalent $\left(\mathrm{PM}_{2.5} \mathrm{e}\right)$ measure based on the health-related social cost of atmospheric release. Section 3 presents the main results based on emission inventories (Sect. 3.1), the POLES-JRC model (Sect. 3.2) and the EMF-30 scenarios (Sect. 3.3). The last section presents a discussion, lays out the main policy conclusions and offers suggestions for future work.

\section{Methods}

The literature on air quality co-benefits typically presents results either in the form of reductions in emissions of air pollutants (e.g. Bertram et al. 2018) or as avoided impacts such as premature mortality (e.g. West et al. 2013). The former approach can result in incomplete answers when not all pollutants are covered, and reporting all pollutants separately does not necessarily facilitate a clear interpretation by and communication to a non-expert audience. The latter approach is preferable, but requires a full impact pathway analysis, including atmospheric chemistry and human health impact modelling, and is thus computationally heavier.

Here, we develop an alternative method that lies between abovementioned approaches and can be described by the use of a $\mathrm{PM}_{2.5}$-equivalent metric that represents a composite measure of air pollutant emissions, aggregating various pollutants based on their damage. In a first step, we run simulations with the atmospheric chemistry model TM5-FASST (Van Dingenen et al. $2018 \mathrm{~b}$ ). We reduce emissions of a specific pollutant by $1 \%$ from a base case (Lamarque et al. 2010) and derive the avoided premature deaths from the corresponding changes in $\mathrm{PM}_{2.5}$ concentration and tropospheric ozone $\left(\mathrm{O}_{3}\right)$ mixing ratio (Table $\mathrm{S} 1$ in Supplementary Information). The result is the marginal social cost by pollutant and region. Because the focus of this paper lies on localised incentives for global climate action, we include only the health impacts within a region in the main results. Total impacts, including health effects that occur outside the source region of emissions, are included in the Supplementary Information (Table S2) and are used only for a sensitivity analysis in Sect. 3.4. Exposure-response functions for $\mathrm{PM}_{2.5}$ are based on the Global Burden of Disease Study 2017 (Stanaway et al. 2018) and cover six disease types: chronic obstructive pulmonary disease, lung cancer, lower respiratory infections, diabetes mellitus type 2, ischemic heart disease and stroke. For ozone, mortality from respiratory causes is based on exposure-response functions from Jerrett et al. (2009). In a second step, we use the health impact per unit of emissions (Table S1) to derive region-specific weights relative to primary $\mathrm{PM}_{2.5}$ for all major air pollutants. The $\mathrm{PM}_{2.5}$-equivalent measure then uses these weights $w$ to aggregate the emissions $E$ of various pollutants $p$ into a composite measure according to the following formula for a region $i$ :

$$
P M_{2.5} e_{i}=\sum_{p} w_{i, p} E_{i, p}
$$

Weights $w_{i, p}$ reflect the relative damage of different air pollutants and are obtained by dividing premature deaths per tonne of emissions by those of primary $\mathrm{PM}_{2.5}$. Differential toxicity across PM components is not considered here. The choice of primary $\mathrm{PM}_{2.5}$ as a numeraire facilitates interpretation but does not affect the relative contribution of pollutants to the total $\mathrm{PM}_{2.5^{-}}$ equivalent. 
This composite metric has advantages in terms of expositional ease and is easily translated into monetary terms. Emissions from a given source usually come as a mix of pollutants contributing to $\mathrm{PM}_{2.5}$ and ozone, and policy targets are typically phrased to cover multiple co-emitted pollutants, which could provide further rationale for our approach. For the monetary valuation of avoided premature deaths, we use a constant value of statistical life (VSL) of \$2 million (2015) throughout the paper, applied uniformly across all regions to facilitate comparison over space and time. This approach therefore does not consider stated or revealed preference studies indicating that VSL rises with income. For a discussion, we refer to Masterman and Viscusi (2018).

Our approach has some similarities with the $\mathrm{CO}_{2}$-equivalent metric, where the weights can be interpreted as global warming potential. The weights $w_{i, p}$ in eq. (1) above could analogously be labelled as the (health) impact potential. Here, we include only premature mortality, but future work could broaden the coverage of impact categories. Importantly, the pollutant weighting scheme is region-specific as atmospheric composition and impact per unit of emissions differ across regions (Anenberg et al. 2011). Conceptually, the method we develop here has similarities with the work on the social cost of atmospheric release (Shindell 2015). As a by-product of our analysis, we produce region-specific estimates of the social cost of atmospheric release, including only premature mortality impacts and derived by netting out all emissions rather than looking at marginal changes in pollutant emissions. For comparison, the global average social costs of black carbon and organic carbon derived here are approximately one third lower than the respective values of $\$ 71,000$ and $\$ 59,000$ per tonne (converted to \$2015) presented in Shindell (2015) after correcting for VSL differences. This difference can be largely attributed to updated estimates for $\mathrm{PM}_{2.5}$-related mortality and exposure-response functions (Stanaway et al. 2018). Furthermore, the method we use in this paper relates to the literature on 'exchange rates' for air pollutant emissions in permit trading schemes (Klaassen et al. 1994; Muller and Mendelsohn 2009) and is also used in life cycle assessments (van Zelm et al. 2016).

Results presented in the following section build on three complementary inputs: inventory data from CEDS (Hoesly et al. 2018) and EDGAR for $\mathrm{N}_{2} \mathrm{O}$ emissions (Crippa et al. 2018), the global energy system model POLES-JRC (Després et al. 2018) with air pollutant emissions based on GAINS Eclipse v5a (IIASA 2015) and the dataset behind the model inter-comparison of the Energy Modeling Forum 30 on shortlived climate forcers and air quality (more details on the EMF-30 scenarios are provided in Supplementary Information). We do not compare results directly as the perimeter may differ both in terms of gases $\left(\mathrm{CO}_{2}, \mathrm{CH}_{4}\right.$ and $\mathrm{N}_{2} \mathrm{O}$ in inventory data and EMF-30; all Kyoto gases in POLES-JRC) and precise sector coverage. The inventory-based analysis is backward-looking and aims to provide an overview of the current state of (sector contributions to) emissions of greenhouse gases and air pollutants. The second result subsection looks into the future by comparing air pollution pathways under various climate policy settings. The third result section is similar in its approach, but expands the numbers of models from one to many in order to get more robust results and a richer understanding of potential outcomes. For brevity, we refer to the sector that covers (energy use in) residential and commercial buildings as 'the residential sector' throughout the paper. The transport sector includes all modes. 


\section{Results}

\subsection{Exploring co-benefit potential}

To get a first idea on where the potential for an atmospheric double dividend is large, we explore inventory data that contains region- and sector-specific information on emissions for historic years. To this end, we use CEDS data (Hoesly et al. 2018), combined with EDGAR data (Crippa et al. 2018) for $\mathrm{N}_{2} \mathrm{O}$ emissions. Figure 1 depicts sector contributions to greenhouse gas emissions (horizontal axis) against the share in air pollutant emissions (vertical axis), represented by the $\mathrm{PM}_{2.5}$-equivalent metric described in Sect. 2, for all countries in the world averaged over the period 2010-2014. The size of the circles corresponds to the 2010-2014 average level of greenhouse gases emitted by the sectors, which are differentiated by colour. The boxplots display the (10th90th percentile) ranges across countries and illustrate that countries differ substantially in their emission sources, both for greenhouse gases (GHG) and for air pollutants.

The residential sector, which includes energy use in commercial buildings, generally represents a relatively small share in terms of GHG emissions. In some countries, the residential sector is the main source of air pollutant emissions, mostly driven by high shares in emissions of primary $\mathrm{PM}_{2.5}$ (black and organic carbon), although Fig. 1 illustrates a wide spread across countries. In Nigeria, the residential sector represents more than $80 \%$ of $\mathrm{PM}_{2.5} \mathrm{e}$ emissions, compared to less than $20 \%$ in the US (Table 1). The energy sector, including electricity generation, petroleum refining and the manufacture of solid fuels, shows the closest correlation between the shares in $\mathrm{CO}_{2} \mathrm{e}$ and $\mathrm{PM}_{2.5} \mathrm{e}$. The linear regression through the origin (estimated coefficient of 0.91 and $R^{2}$ of 0.79 ) is close to the $45^{\circ}$ degree line, which indicates that this sector contributes to greenhouse gas and air pollutant emissions to a comparable extent in most countries. A number of observations indicate shares above $50 \%$ for both $\mathrm{CO}_{2} \mathrm{e}$ and $\mathrm{PM}_{2.5} \mathrm{e}$, including the energy sectors in Serbia and Kuwait. A similar pattern can be observed for the transport sector (all transport modes are included in Fig. 1 and Table 1), with typically a contribution to greenhouse gas and air pollutant emissions that is more modest than the energy sector. Emissions from industry, here covering emissions from processes and solvents as well as from energy combustion, tend to have a higher share in GHG emissions than in air pollution, although this does not hold for all countries. Brazil is a notable exception, where primary $\mathrm{PM}_{2.5}$ emissions in the food and tobacco sector are relatively high compared to the sector's GHG emissions (and to a lesser extent also for $\mathrm{SO}_{2}$ emissions relative to GHG in non-metallic minerals). The variation across countries is large for the sector covering agriculture and waste, for which the shares in country total GHG emissions are typically larger than the sector's share in $\mathrm{PM}_{2.5} \mathrm{e}$ emissions. Results for Egypt show the largest contribution for the agriculture and waste sector, which is partially driven by large primary $\mathrm{PM}_{2.5}$ emissions from waste combustion.

The approach we use here is relatively straightforward and despite its simplicity produces source attribution results that are generally in agreement with studies such as Lelieveld et al. (2015) and Silva et al. (2016). Table 1 shows sector contributions for the countries that rank in the top 20 of total GHG or black carbon emissions in 2014. Bold numbers highlight the country maximum, while numbers in italics indicate the maximum across all countries shown. Broadly speaking, energy and agriculture are relatively important for GHG and air pollutant emissions, respectively, for both Europe and North America; the residential sector appears as a major source of air pollution in Asia and Africa; and in fossil fuel-producing countries such as Iran, Saudi Arabia and Russia, the energy and industry sectors contribute significantly to both $\mathrm{CO}_{2} \mathrm{e}$ and $\mathrm{PM}_{2.5} \mathrm{e}$ emissions. These patterns and the orders of magnitude match fairly well with Lelieveld et al. (2015) and Silva et al. 

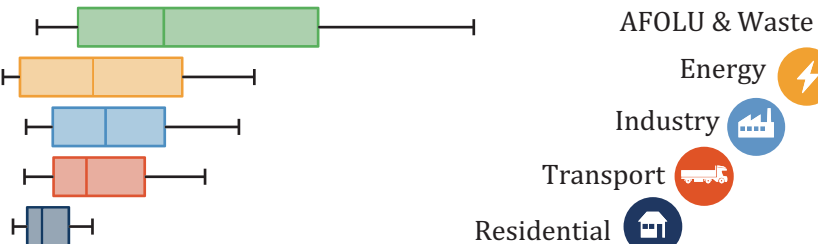

Residential

\section{I}

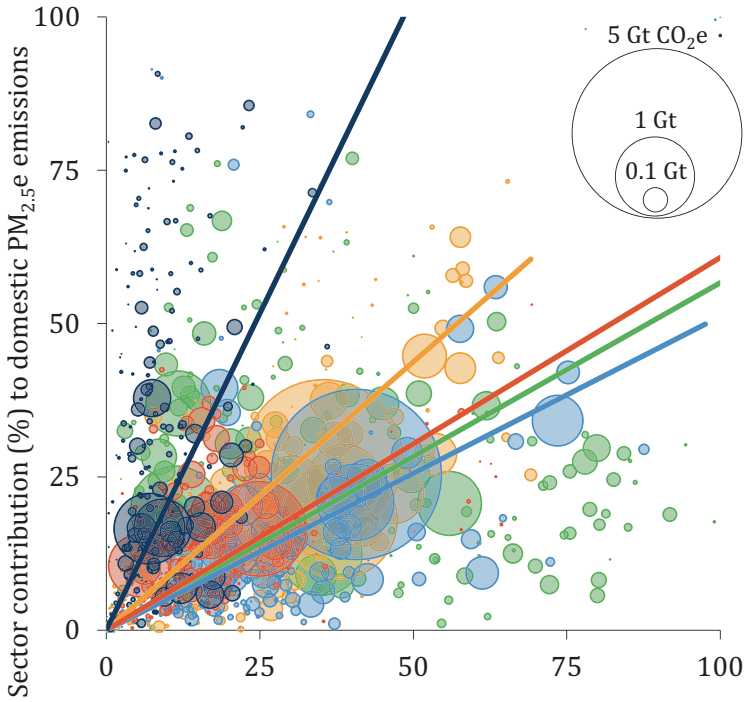

Sector contribution (\%) to domestic $\mathrm{CO}_{2}$ e emissions
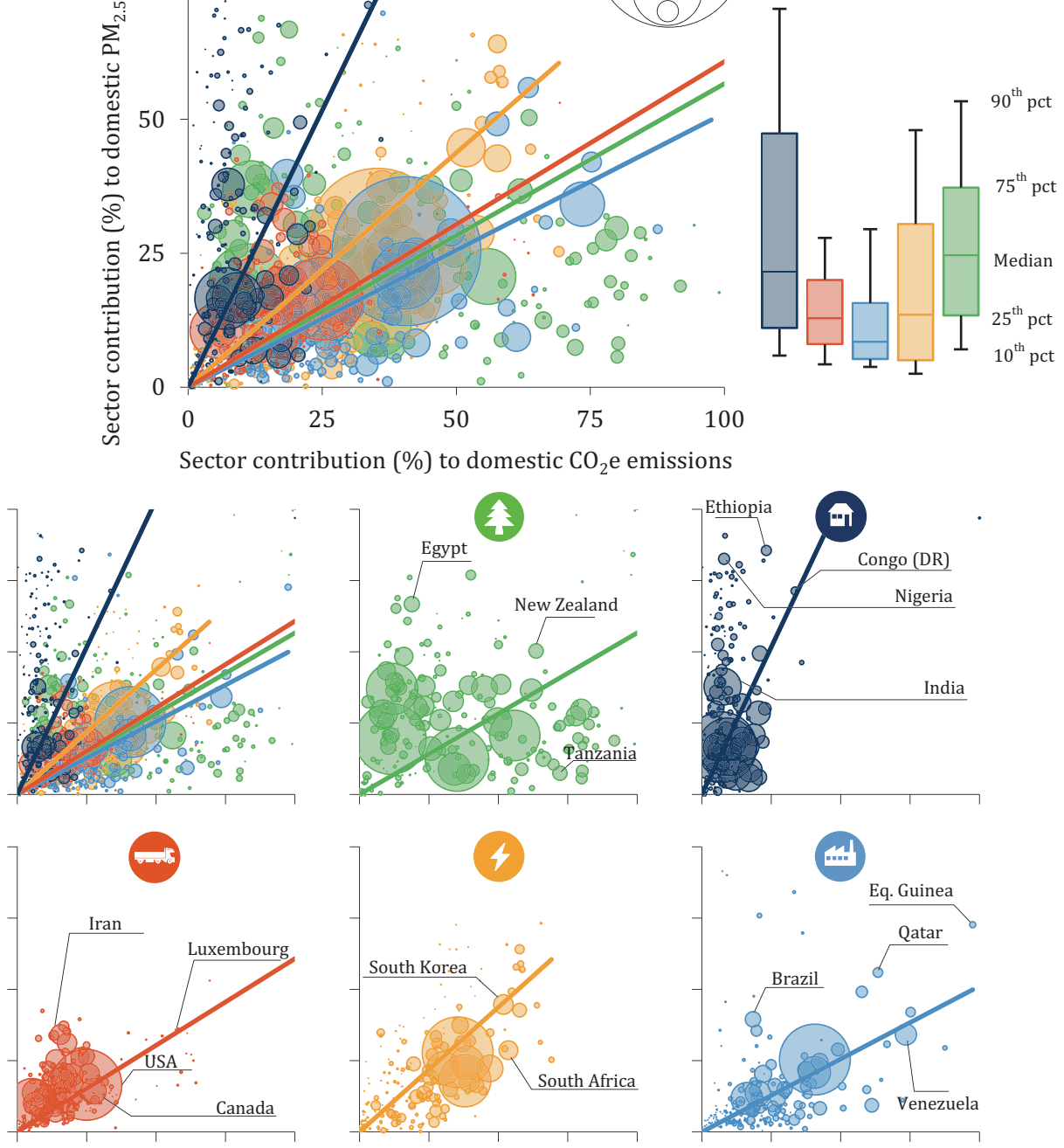

Fig. 1 Sector shares in greenhouse gases and air pollutants across 218 countries averaged over the period 20102014. Energy: energy supply; industry: energy combustion in industry, process emissions and solvents; residential: residential and commercial buildings; transport: all transport modes. Source: own calculations based on CEDS (Hoesly et al. 2018) and EDGAR (Crippa et al. 2018) for $\mathrm{N}_{2} \mathrm{O}$ emissions in 2012 
(2016), although the numbers are not directly comparable due to different coverage, sector aggregation and year. For China and India, we obtain larger contributions of energy and industry sectors, while the air pollution impact attributed to agriculture in the US is higher than in abovementioned studies. For Japan, Turkey and Russia, the finding that the agriculture sector is the major contributor to air local pollution confirms the results of Lelieveld et al. (2015), although our numbers attribute a higher share to industry in Russia.

The numbers presented here come with several caveats that should be considered in the interpretation. First, air pollutants such as black carbon can have an impact on global warming, while others such as $\mathrm{SO}_{2}$ reflect sunlight back into the atmosphere and have a cooling effect on the planet. The global warming potential of aerosols is not included in Fig. 1. Second, methane acts as a precursor for ozone formation and hence contributes to the health effects of air pollution. This effect happens at a global level and is unrelated to the source region. Therefore,

Table 1 Sector shares (\%) in greenhouse gases and air pollutants across countries averaged over the period 2010-2014. Bold numbers highlight the country (row) maximum for GHG and PM numbers in italics indicate the (column) maximum across all countries shown. Source: own calculation based on CEDS (Hoesly et al. 2018) and EDGAR (Crippa et al. 2018)

\begin{tabular}{|c|c|c|c|c|c|c|c|c|c|c|}
\hline & \multicolumn{2}{|c|}{ Energy } & \multicolumn{2}{|c|}{ Transport } & \multicolumn{2}{|c|}{ Residential } & \multicolumn{2}{|c|}{ Industry } & \multicolumn{2}{|c|}{ AFOLU and waste } \\
\hline & GHG & $\mathrm{PM}_{2.5} \mathrm{e}$ & GHG & $\mathrm{PM}_{2.5} \mathrm{e}$ & GHG & $\mathrm{PM}_{2.5} \mathrm{e}$ & GHG & $\mathrm{PM}_{2.5} \mathrm{e}$ & GHG & $\mathrm{PM}_{2.5} \mathrm{e}$ \\
\hline \multicolumn{11}{|l|}{ North America } \\
\hline Canada & 23 & 14 & 27 & 14 & 11 & 16 & 26 & 16 & 13 & 40 \\
\hline United States & 38 & 18 & 25 & 17 & 9 & 17 & 16 & 12 & 12 & 37 \\
\hline \multicolumn{11}{|l|}{ Europe } \\
\hline France & 12 & 6 & 26 & 20 & 20 & 29 & 19 & 7 & 24 & 38 \\
\hline Germany & 40 & 18 & 17 & 14 & 15 & 17 & 18 & 8 & 10 & 43 \\
\hline United Kingdom & 33 & 15 & 20 & 17 & 17 & 9 & 0 & 0 & 16 & 48 \\
\hline \multicolumn{11}{|l|}{ Latin America } \\
\hline Brazil & 6 & 9 & 17 & 20 & 3 & 11 & 18 & 40 & 56 & 21 \\
\hline Mexico & 26 & 19 & 20 & 20 & 5 & 15 & 30 & 15 & 20 & 30 \\
\hline Venezuela & 8 & 35 & 7 & 13 & 1 & 2 & 74 & 34 & 10 & 17 \\
\hline \multicolumn{11}{|l|}{ Asia } \\
\hline China & 35 & 28 & 5 & 11 & 7 & 17 & 41 & 25 & 11 & 19 \\
\hline India & 30 & 22 & 7 & 14 & 7 & 38 & 20 & 14 & 35 & 12 \\
\hline Japan & 47 & 22 & 16 & 18 & 12 & 7 & 22 & 20 & 3 & 33 \\
\hline Indonesia & 19 & 24 & 14 & 25 & 5 & 30 & 27 & 12 & 34 & 9 \\
\hline Pakistan & 11 & 7 & 8 & 6 & 6 & 53 & 26 & 9 & $\mathbf{5 0}$ & 25 \\
\hline South Korea & 52 & 45 & 14 & 6 & 9 & 5 & 19 & 14 & 6 & 29 \\
\hline Thailand & 25 & 21 & 15 & 13 & 6 & 16 & 25 & 24 & 29 & 26 \\
\hline Viet Nam & 13 & 6 & 9 & 6 & 7 & 39 & 38 & 16 & 34 & 33 \\
\hline \multicolumn{11}{|c|}{ Middle East and Africa } \\
\hline Algeria & 13 & 3 & 11 & 20 & 7 & 44 & 61 & 9 & 8 & 24 \\
\hline Dem. Rep. Congo & 0 & 0 & 7 & 2 & 34 & 71 & 6 & 15 & 53 & 12 \\
\hline Egypt & 27 & 3 & 13 & 15 & 8 & 11 & 33 & 4 & 19 & 67 \\
\hline Ethiopia & 0 & 0 & 4 & 3 & 23 & 86 & 14 & 2 & 58 & 9 \\
\hline Iran & 21 & 12 & 16 & 34 & 17 & 6 & 38 & 22 & 9 & 26 \\
\hline Nigeria & 9 & 1 & 10 & 3 & 8 & 83 & 35 & 6 & 38 & 7 \\
\hline Saudi Arabia & 36 & 37 & 18 & 31 & 1 & 0 & 42 & 25 & 3 & 7 \\
\hline South Africa & 54 & 29 & 9 & 6 & 5 & 36 & 0 & 0 & 12 & 21 \\
\hline Tanzania & 3 & 2 & 6 & 5 & 6 & 77 & 13 & 9 & 72 & 7 \\
\hline \multicolumn{11}{|l|}{ Other } \\
\hline Australia & 37 & 31 & 14 & 8 & 4 & 9 & 0 & 0 & 26 & 16 \\
\hline Russia & 39 & 24 & 6 & 10 & 6 & 17 & 41 & 21 & 9 & 28 \\
\hline Turkey & 26 & 27 & 10 & 14 & 14 & 20 & 0 & 0 & 23 & 31 \\
\hline
\end{tabular}


we do not include ozone-related health impacts from methane in Fig. 1, but explore the sensitivity of some of our results with respect to this choice in Sect. 3.4. Here, we use only within-region effects because we want to emphasise local incentives for climate policy. Third, the underlying dataset on GHG emissions only includes $\mathrm{CO}_{2}, \mathrm{~N}_{2} \mathrm{O}$ and $\mathrm{CH}_{4}$, so the contribution of sectors to climate change by emissions of fluorinated gases is not taken into account. Furthermore, note that regression lines are not weighted by the size of population or emissions.

\subsection{Air quality co-benefits in $1.5{ }^{\circ} \mathrm{C}$ and $2{ }^{\circ} \mathrm{C}$ scenarios}

Understanding the sources of emissions is not sufficient to derive conclusions on where-in which region and sector-mitigation action will yield the largest co-benefits. Some GHG abatement technologies or low-carbon fuels will not necessarily translate into air quality improvements (e.g. bioenergy), while other measures have potentially large co-benefits but may be more costly to implement. Compared to a multi-model ensemble, the use of one energy system model provides more flexibility in terms of scenario design and regional disaggregation. In this section, we use the POLES-JRC model to quantify the value of air quality co-benefits in the two scenarios that are setting the scene for international climate policy negotiations, limiting global warming to $2{ }^{\circ} \mathrm{C}$ and $1.5^{\circ} \mathrm{C}$ by the end of the century. We furthermore illustrate the importance of technology choices by including a variant of the $2{ }^{\circ} \mathrm{C}$ scenario with more use of modern biomass (HiBio). This ambitious biomass scenario uses a long-term biomass supply potential of $300 \mathrm{EJ} / \mathrm{year}$, compared to $180 \mathrm{EJ} /$ year for the central $2{ }^{\circ} \mathrm{C}$ scenario (see Keramidas et al. 2018 for more background and scenario description). The value of co-benefits is calculated by first multiplying pollutant emission reductions compared to a reference that includes current policy measures $\left(\Delta E_{i, p}\right)$ with the social cost of atmospheric release $\left(S C A R_{i, p}\right)$, and then dividing by the change in GHG emissions between the scenario and the current policy baseline $(\triangle G H G)$. As discussed in Sect. 2, the social cost of atmospheric release here only includes the monetary valuation of premature mortality. Alternatively, the calculation can be phrased as the value of $\mathrm{PM}_{2.5}$-equivalent (see Sect. 2) reduction per tonne of GHG abatement:

$$
\begin{gathered}
\text { Co - benefit value in region } i=\frac{\sum_{p} \Delta E_{i, p} * S C A R_{i, p}}{\Delta G H G_{i}} \\
=\frac{\Delta P M_{2.5} e_{i} * S C A R_{i, \text { Primary } P M 2.5}}{\Delta G H G_{i}}
\end{gathered}
$$

Results are presented in Fig. 2, which contains GHG emission reduction (horizontal axis) and air quality co-benefit values per tonne of $\mathrm{CO}_{2} \mathrm{e}$ abated (vertical axis) by sector. The total value of air quality co-benefits in a sector then corresponds to a rectangle formed by connecting a particular point in the graph with the axes and the origin. Points with equal value of total cobenefits are represented by isoquants to facilitate a comparison across sectors within a country.

The results indicate high co-benefit values per tonne of $\mathrm{CO}_{2} \mathrm{e}$ abated for the transport and residential sectors in Poland, Sub-Sahara Africa, China and India, while the agriculture, forestry, land use and waste and transport sectors rank high relative to other sectors in terms of co-benefits per tonne of $\mathrm{CO}_{2} \mathrm{e}$ abated in France, Germany and the USA. In France, a country with a strong reliance on nuclear energy, the transport sector appears as the sector with both the highest GHG reductions and the highest total co-benefits in the $1.5^{\circ} \mathrm{C}$ scenario in 2050. In Brazil and Sub-Sahara Africa, the agriculture, forestry and land use (AFOLU) and waste sector plays an important role in mitigating GHG emissions, but potential co-benefits of land use measures on forest fires and biodiversity are 

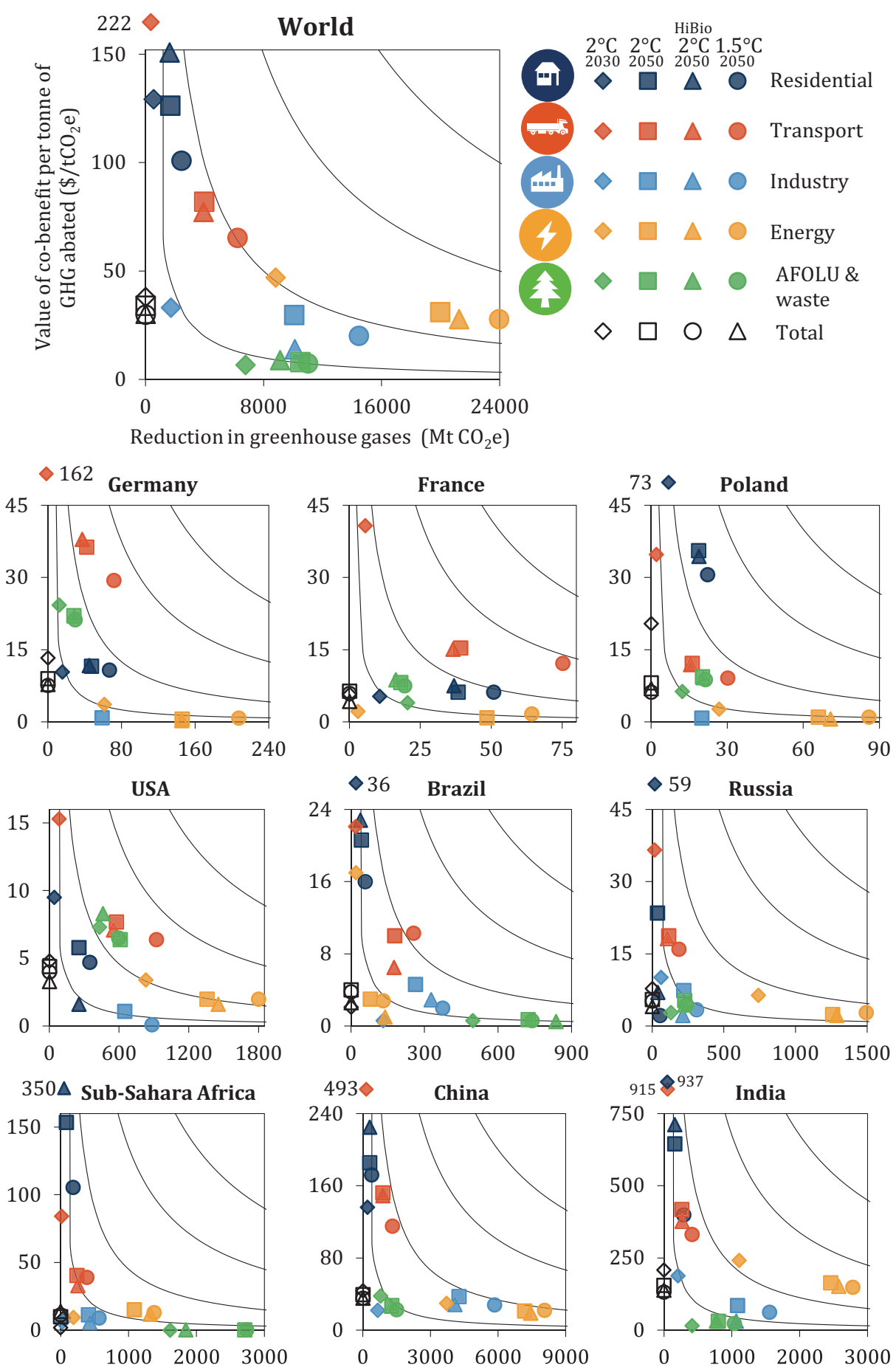

Fig. 2 Comparing relative (per tonne of abated greenhouse gas emissions) and absolute co-benefits. Isoquants represent points with equal absolute co-benefits. Source: own calculations with the POLES-JRC model 
not captured by the analysis. The absolute value of air quality co-benefits, obtained by multiplying $\mathrm{x}$ and $y$ coordinates of a point in the figure, is highest in the energy sector on the global level due to the volume of GHG abated. Figure 2 furthermore shows that the co-benefits per tonne of $\mathrm{CO}_{2} \mathrm{e}$ abated fall over time (2030-2050) and with climate policy ambition $\left(2-1.5^{\circ} \mathrm{C}\right)$. These decreasing returns of scale effect are more than compensated by higher volumes of GHG reduction such that the total co-benefits increase both over time and with climate policy ambition. The finding that marginal cobenefits decrease with climate policy stringency confirms previous work (Thompson et al. 2014) and suggests that the least costly GHG reduction measures may have relatively high co-benefits, such as a coal phase-out (Driscoll et al. 2015) and energy efficiency improvements (Grubler et al. 2018; Buonocore et al. 2016).

A higher uptake of modern biomass lowers co-benefits per tonne of $\mathrm{CO}_{2} \mathrm{e}$ abated in most sectors, but not in the residential sector in low-income countries. The HiBio scenario results in a larger contribution of biofuels to the overall fuel mix in the transport sector, which lowers the importance of other mitigation options such as electrification and energy efficiency. On the other hand, in the residential sector we observe a shift from traditional to modern biomass in the countries where the use of traditional biomass in buildings plays an important role. Higher modern biomass use puts pressure on land, which leads to lower availability and use of traditional biomass. At the same time, higher modern biomass use results in fewer GHG emissions reductions from the AFOLU and waste sector and more from the energy sector on a global level.

\subsection{Sectoral air quality co-benefits: multi-model ensemble}

This section expands the previous one by looking at air pollution changes across three broadbased climate policy scenarios (compared to a reference) performed by a set of ten integrated assessment models in the context of the Energy Modeling Forum (EMF 2019) on short-lived climate forcers and air quality (EMF-30): AIM/CGE, DNE21+, EC-IAM, ENV-Linkages, GCAM, IMAGE, MESSAGE-GLOBIOM, POLES, REMIND and WITCH-GLOBIOM. These models have been previously used in energy and climate policy research, as described for instance by Krey et al. (2019), Riahi et al. (2017), Luderer et al. (2017), Kriegler et al. (2014, 2015), Tavoni et al. (2015) and Van Vuuren et al. (2011). More information can be found in Supplementary Information and is presented in Harmsen et al. (2019b, 2019c). Other studies in the EMF-30 exercise include Harmsen et al. (2019a), Smith et al. (2019), Rauner et al. (2019) and Chantret et al. (2019). Comparing the outcomes on air quality co-benefits across different models can provide more robust results, as the contribution of different mitigation options and low-carbon technologies to climate change mitigation will depend on the assumptions of a specific model. From the EMF-30 scenario ensemble, we select the three scenarios that represent broad-based climate change mitigation policy covering all Kyoto greenhouse gases: 'Climate Policy' in line with a $2{ }^{\circ} \mathrm{C}$ target, 'Slower Action' resembling Nationally Determined Contributions (NDCs) and a 'Slower to faster' bridging scenario that starts off with NDCs until 2030 but still aims to meet the

$2{ }^{\circ} \mathrm{C}$ target. These scenarios are then compared with a reference without climate policy.

The air quality co-benefits per tonne of greenhouse gas emissions abated displayed in Fig. 3 were derived by first calculating the reductions in air pollutant emissions per tonne of greenhouse gases abated. Next, we convert this to a monetary co-benefit value $\left(\$ 2015\right.$ per tonne of $\left.\mathrm{CO}_{2} \mathrm{e}\right)$ by multiplying emission reductions with their corresponding region- and pollutant-specific health impact cost as derived from the atmospheric chemistry and health modelling laid out in Sect. 2 (see Table S1). An equivalent way to explain the method would be to say that we convert air 


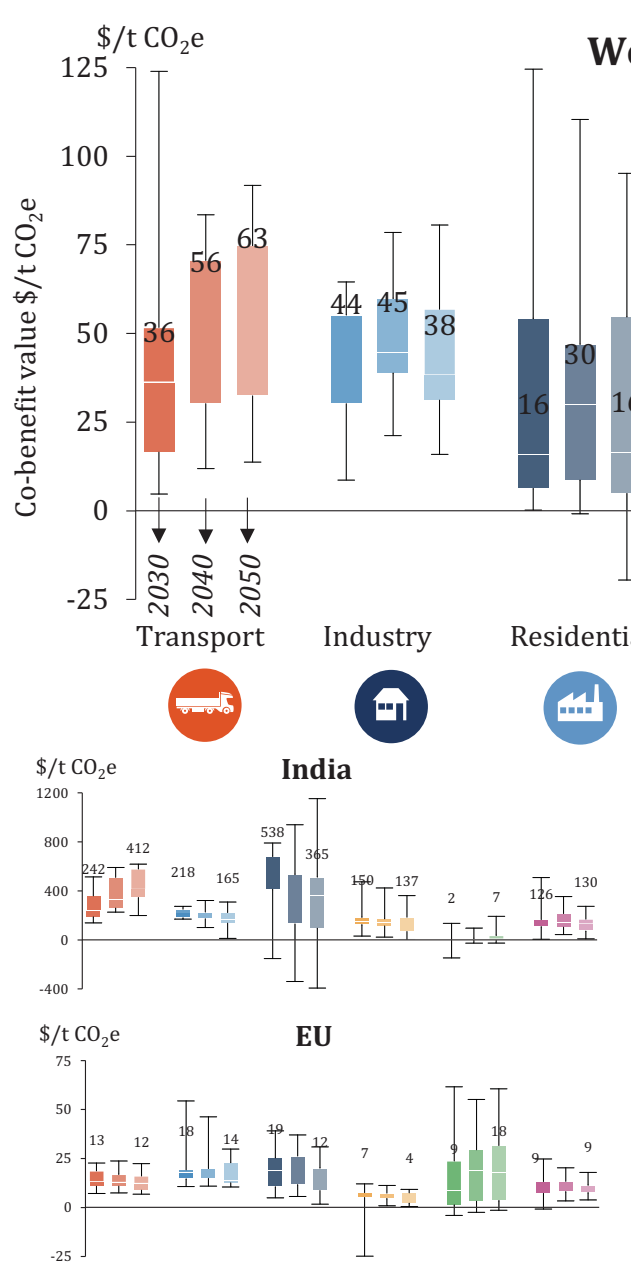

World
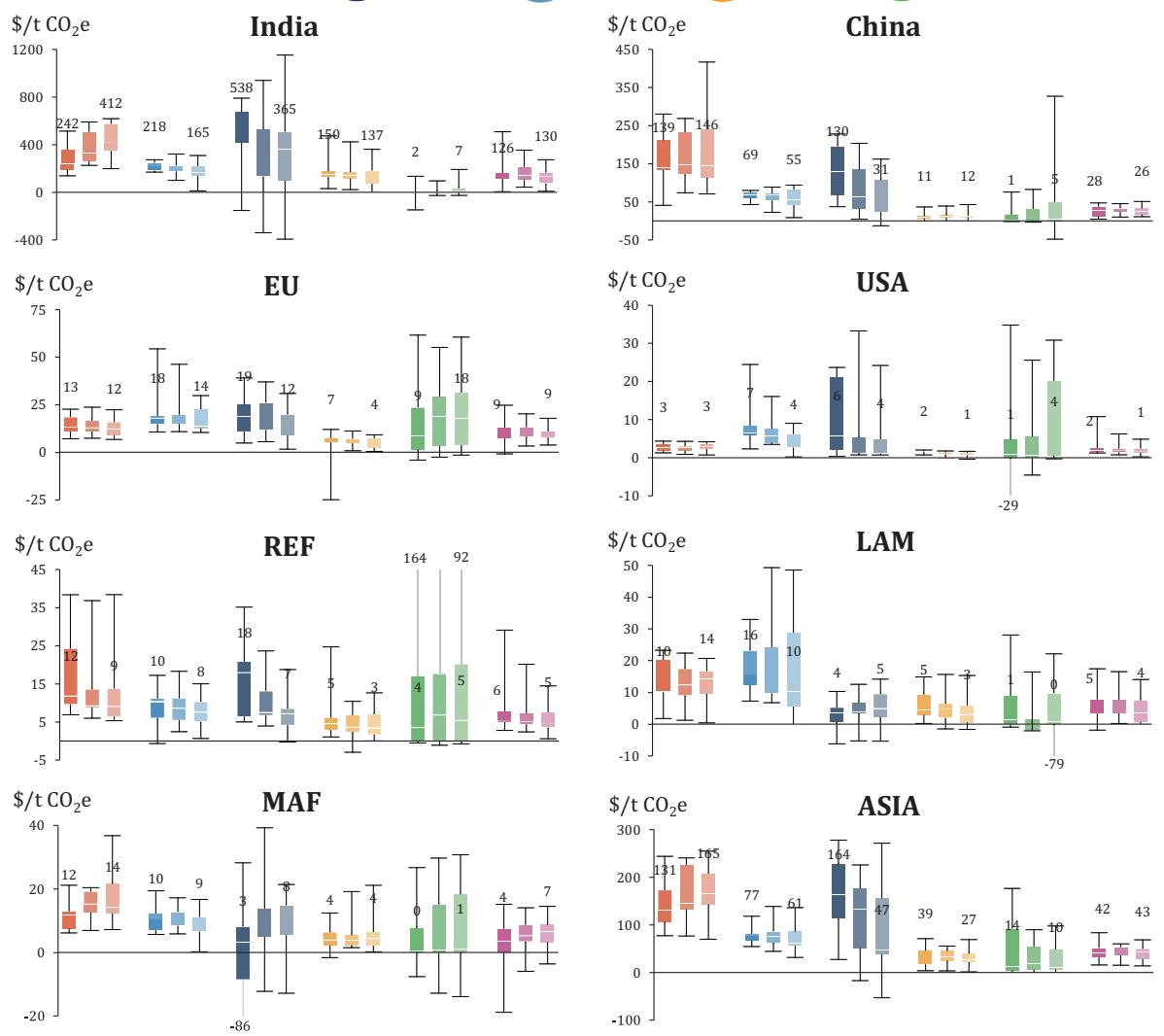

Fig. 3 Value of health-related air quality co-benefits of climate policy across sectors and regions for the multi-model ensemble of EMF-30 for the period 2020-2050 in 10-year steps. Latin America, LAM; Middle East and Africa, MAF; reforming economies including Russia, Ukraine, Poland and others, REF. Full region definition can be found in SI. Boxplots show 25th, 50th and 75th percentile with whiskers covering the full range of results from up to 10 models and 3 scenarios. Numbers displayed in the figure correspond to the median value across models and scenarios. Source: own calculations based on the EMF-30 database composed of scenario results from 10 integrated assessment models 
pollutant emissions to $\mathrm{PM}_{2.5}$-equivalent emissions (as explained in Sect. 2) and then monetise the cobenefits by multiplying with the average social cost of primary $\mathrm{PM}_{2.5}$.

A number of insights appear from Fig. 3. First, global economy-wide co-benefits range between $\$ 8$ and $\$ 40 / \mathrm{tCO}_{2} \mathrm{e}$ in 2030 , with median value of $\$ 18 / \mathrm{tCO}_{2} \mathrm{e}$. These results are within the range presented by Nemet et al. (2010) and are lower than the estimated second-best domestic prices of $\$ 63 / \mathrm{tCO}_{2}$ (converted to 2015 values) of Parry et al. (2015), although our results do not compare directly with the latter due to different coverage of GHG, regions and impact categories. Results for the USA are lower than those presented by Thompson et al. (2014) and Zhang et al. (2017), primarily due to differences in mortality valuation and exposure-response functions for $\mathrm{PM}_{2.5}$.

Second, the resulting air quality co-benefit values reveal a wide divergence in their magnitude across location. Regions with lower population density (USA, Latin AmericaLAM) and a longer history of air pollution control policy (EU, USA) can expect smaller cobenefits than densely populated low-income regions where technology and fuel mix are less favourable for initial levels of air pollution (China, India). Values in India exceed the range of 2-214 \$/ $\mathrm{tCO}_{2}$ (converted to 2015 dollars) in Nemet et al. (2010) for all sectors except agriculture, land use and waste. These results are driven by changes in emissions, how they translate to concentrations and subsequently to human health impacts, but abstract from regional differences in the valuation of avoided premature deaths as we assume a uniform value of $\$ 2$ million per death, irrespective of income and age. Relating the valuation of premature deaths to per capita income on the basis of willingness-to-pay for risk reduction would reduce the gap in co-benefit values between high- and low-income regions. We refrain from adding that additional layer of differentiation here, as our main purpose is to compare cobenefits across regions and sectors. Results can be scaled to match other assumptions on the value of statistical life without much effort; hence, we leave that exercise to readers who have an interest in doing so, for instance to compare with other studies or to translate the results to be used in a policy process where the valuation of avoided premature deaths is prescribed.

Third, differences appear between countries with respect to the relative intensity of cobenefits across sectors. Mitigating greenhouse gas emissions from industrial sources brings about high gains in air quality relative to other sectors in Latin America (LAM), and to some extent also in the USA. In Asia, climate policy impact on air pollutant emissions is largest for buildings (residential and commercial) and for transport. Coal use for heating and cooking and a vehicle fleet that has been subject to less stringent air pollution controls in the past are underlying factors for this result. In the EU, the highest (maximum) air quality co-benefits per tonne of greenhouse gas reduction are found in the sector covering agriculture, land use and waste, mainly due to reductions in ammonia emissions. The spread in EU agriculture cobenefits across models is significant, driven by differences in the modelled response of ammonia emission to climate change policy. Various mitigation technologies exist in agriculture, some of which have strong potential for ammonia reductions (e.g. precision farming), which appears to be reflected in the models that represent the higher end of the agriculture cobenefit estimate for Europe. Interestingly, the energy supply sector does not have the highest value of co-benefits per tonne of $\mathrm{CO}_{2}$ e reductions in any of the regions shown in Fig. 3, although electricity generation has probably received most attention in the academic literature and policy debate (Deng et al. 2018).

Fourth, the co-benefit estimates do not show a pattern over time that is consistent across regions and sectors. Multiple and sometimes counteracting effects influence the evolution over time. Energy tends to be used more efficiently as technology improves, and air pollution 
controls become more stringent over time, reducing the scope for air quality co-benefits. Possibly, some of the relatively inexpensive options to reduce greenhouse gas emissions may give rise to strong air quality co-benefits, such as phasing out coal. Conversely, increasing values over time could arise if technologies exist that are costly from a climate change mitigation perspective (hence are implemented in later years), but have potentially high air quality co-benefits. Furthermore, growing population and rising base mortality rates for the causes of death influenced by air pollution could lead to higher co-benefits in the future. In the results presented here, the valuation of health benefits does not grow over time with income, which could be an additional factor affecting the temporal pattern of co-benefit values.

Fifth, taking into account multiple models, as done in the inter-model comparison here, results in a broad range of co-benefit estimates, spanning both positive and negative values for several region-sector combinations. Both the highest and the lowest values are found in the residential sector in India. The upper end corresponds to (DNE21+) model outcomes characterised by relatively strong reliance on fossil fuels in the residential sector in the benchmark, in combination with a significant reduction of coal and oil use in buildings in response to climate policy. More detailed assumptions, for instance on the evolution of sulphur content of coal burnt by households in the reference, may differ across models and may explain part of the variation in the results. The lower end is driven by (IMAGE-GLOBIOM) model results for which climate policy increases the uptake of traditional biomass in the residential sector. Similarly, (IMAGE-GLOBIOM) model results indicate negative cobenefits due to increased biomass use in the residential sector in the Middle East and Africa (MAF) and due to forest burning in the USA, China and Latin America (LAM). Importantly, these results highlight that air quality co-benefits of climate policy are not guaranteed and depend on policy design. Adopting an integrated perspective on climate, air and land is needed to avoid potential adverse side effects.

\subsection{Sensitivity analysis: local versus global incentives}

In the results presented in the previous sections, we have only considered air pollution damages that occur within the boundaries of the source region. Considering all impacts, including those that arise outside the source region due to transboundary transport of pollutants, could raise the value of co-benefits. Figure S3 in Supplementary Information shows for Germany (POLES-JRC), the US and the world (EMF-30) that the choice whether or not to include transboundary effects in the co-benefit estimate has a limited effect for the large regions in the EMF-30 exercise, but has stronger implications for a smaller country like Germany. For the latter, the overall co-benefit value roughly doubles compared to the estimate that only consider impacts within the country. Including damages from transboundary pollution particularly raises the co-benefits for sectors that reduce pollutant emissions that lead to the formation of secondary $\mathrm{PM}_{2.5}$, such as $\mathrm{NO}_{\mathrm{x}}$ in transport and $\mathrm{SO}_{2}$ in power generation. Adding the impact of methane as a precursor for ozone further raises the co-benefits of greenhouse gas mitigation in the agriculture, forestry, land use and waste sector considerably by $\$ 12 / \mathrm{tCO}_{2} \mathrm{e}$ in 2030 on the global level. This sensitivity analysis therefore highlights the incentive mismatch between local mitigation cost and global gains of methane abatement, which provides a rationale for international collaborations, such as the UN-led Global Methane Alliance, to jointly take action to lower methane emissions, preferably with broad source sector coverage. 


\section{Discussion and conclusion}

From the three approaches adopted, a set of coherent conclusions appears. First, country specifics are crucial to consider when designing integrated climate-air policies. The sector contributions to greenhouse gas and air pollutant emissions vary across space, and so do the ranking of sectors according to air quality co-benefits of climate policy. These results provide arguments for integrated policies to deviate from uniform global and economy-wide carbon pricing in a second-best situation where no additional policy instruments are available. In the real world, several overlapping policies may co-exist. Therefore, our co-benefit estimates could be evaluated against effective carbon tax rates to identify sectors where current pricing fails to reflect air quality externalities. Second, no single sector is a silver bullet when it comes to improving air quality and limiting global warming. Not all sectors contribute equally to the mix of air pollutants, but countries in which one particular sector is the dominating cause for both problems are an exception. Climate change mitigation can yield some degree of co-benefits in all sectors, but typically sectors represent either high GHG reduction potential (such as the energy supply sector) or high co-benefits per tonne of GHG reduced (such as the residential and commercial sector). Third, the value of air pollution co-benefits is substantial in many regions, and often differs widely across sectors. As air pollutionrelated health impacts typically arise in a shorter time frame than climate impacts, the gains of clean air can provide a strong and local incentive for climate action in the near term. From an integrated climate-air perspective, a second-best efficient policy would equalise the marginal co-benefits across sectors. Our results therefore indicate opportunities to ratchet up climate policy ambition in sectors with a high value of co-benefits per tonne of greenhouse gas emissions abated. Essentially, balancing trade-offs and leveraging synergies calls for an encompassing policy framework or pricing scheme that covers multiple externalities, providing the incentives for sustainable solutions in a broad sense. In absence of this encompassing framework, (sector-specific) measures could be designed to obtain an 'atmospheric double dividend', capturing the synergies between climate mitigation and clean air.

On the methodological front, we aggregate results for air pollutants here by adopting a $\mathrm{PM}_{2.5}$-equivalent weighting scheme based on air pollutant damage estimates. While this approach can be refined in various ways, we believe it offers a useful way to aggregate and present information. The region-specific social cost of atmospheric release we derived, although limited in coverage to premature mortality, is an output on itself that can be a useful input for other research and for cost-benefit assessments. One direction for future work could be to expand the coverage to include other effects of air pollution, such as morbidity and ozone-related crop yield impacts. Second, future research could take air pollution control policy as an entry point, and study its consequences for climate change. Third, comparing co-benefits across various policy instruments (e.g. taxes, permits, regulation) and mitigation actions (e.g. energy efficiency, lifestyle change) could complement the sector-specific perspective we adopt in the present study. Fourth, a higher level of technological detail can be useful for policy guidance. Finally, we rely on only one atmospheric chemistry model; a multi-model ensemble could derive more robust estimates of the region- and pollutant-specific social cost of atmospheric release. Compared to the social costs calculated with three reducedcomplexity models in Gilmore et al. (2019), our numbers for damages from $\mathrm{NO}_{\mathrm{x}}$ and 
$\mathrm{SO}_{2}$ relative to those from primary fine particulate matter in the USA are 2-8 times lower, which has implications for the cross-sectoral comparison of co-benefits.

\section{Compliance with ethical standards}

Disclaimer The views expressed are purely those of the authors and may not in any circumstances be regarded as stating an official position of the European Commission.

Open Access This article is licensed under a Creative Commons Attribution 4.0 International License, which permits use, sharing, adaptation, distribution and reproduction in any medium or format, as long as you give appropriate credit to the original author(s) and the source, provide a link to the Creative Commons licence, and indicate if changes were made. The images or other third party material in this article are included in the article's Creative Commons licence, unless indicated otherwise in a credit line to the material. If material is not included in the article's Creative Commons licence and your intended use is not permitted by statutory regulation or exceeds the permitted use, you will need to obtain permission directly from the copyright holder. To view a copy of this licence, visit http://creativecommons.org/licenses/by/4.0/.

\section{References}

Anenberg SC, Talgo K, Arunachalam S, Dolwick P, Jang C, West JJ (2011) Impacts of global, regional, and sectoral black carbon emission reductions on surface air quality and human mortality. Atmos Chem Phys 11(14):7253-7267

Anenberg SC et al (2012) Global air quality and health co-benefits of mitigating near-term climate change through methane and black carbon emission controls. Environ Health Perspect 120(6):831-839

Bertram C et al (2018) Targeted policies can compensate most of the increased sustainability risks in $1.5 \mathrm{C}$ mitigation scenarios. Environ Res Lett 13(6):064038

Buonocore JJ, Luckow P, Norris G, Spengler JD, Biewald B, Fisher J, Levy JI (2016) Health and climate benefits of different energy-efficiency and renewable energy choices. Nat Clim Chang 6(1):100

Chantret F, Chateau J, Dellink R, Durand-Lasserve O, Lanzi E (2020) Can better technologies avoid all air pollution damages to the global economy? Clim Chang

Crippa M et al (2018) Gridded emissions of air pollutants for the period 1970-2012 within EDGAR v4. 3.2. Earth System Science Data 10:1987-2013

Deng HM, Liang QM, Liu LJ, Anadon LD (2018) Co-benefits of greenhouse gas mitigation: a review and classification by type, mitigation sector, and geography. Environ Res Lett 12(12):123001

Després J et al. (2018) POLES-JRC model documentation-updated for 2018. JRC Technical Report, No. JRC113757. Joint Research Centre (Seville site)

Driscoll CT et al (2015) US power plant carbon standards and clean air and health co-benefits. Nat Clim Chang 5(6):535

EMF (2019) Energy Modeling Forum (EMF)-30 study on short-lived climate forcers (SLCF) and air quality. https:/emf.stanford.edu/projects/emf-30-short-lived-climate-forcers-air-quality

Harmsen M, van Dorst P, van Vuuren DP, van den Berg M, Van Dingenen R, Klimont Z (2019a) Co-benefits of black carbon mitigation for climate and air quality. Clim Chang (in review)

Harmsen $\mathrm{M}$ et al (2019b) The role of methane in future climate strategies: mitigation potentials and climate impacts. Clim Chang:1-17

Harmsen M et al. (2019c) Taking some heat off the NDCs? The limited potential of additional short-lived climate forcers' mitigation. Clim Chang, 1-19.IIASA (2015). ECLIPSE v5a global emissions online database. International Institute for Applied Statistical Analysis, Laxenburg

Hoesly RM et al (2018) Historical (1750-2014) anthropogenic emissions of reactive gases and aerosols from the Community Emissions Data System (CEDS). Geoscientific Model Development 11(1):369-408

IPCC (2018). Special report: global warming of $1.5^{\circ} \mathrm{C}$ (eds V. Masson-Delmotte. et al.), Cambridge Univ. Press

Gilmore EA, Heo J, Muller NZ, Tessum CW, Hill J, Marshall J, Adams PJ (2019) An inter-comparison of air quality social cost estimates from reduced-complexity models. Environ Res Lett

Grubler A et al (2018) A low energy demand scenario for meeting the $1.5 \mathrm{C}$ target and sustainable development goals without negative emission technologies. Nat Energy 3(6):515 
Jerrett M et al (2009) Long-term ozone exposure and mortality. N Engl J Med 360(11):1085-1095

Keramidas, K., et al. (2018). Global energy and climate outlook 2018: Sectoral mitigation options towards a lowemissions economy, JRC Science for Policy Report (No. JRC113446)

Krey V et al (2019) Looking under the hood: a comparison of techno-economic assumptions across national and global integrated assessment models. Energy 172:1254-1267

Kriegler E et al (2014) The role of technology for achieving climate policy objectives: overview of the EMF 27 study on global technology and climate policy strategies. Clim Chang 123(3-4):353-367

Kriegler E et al (2015) Making or breaking climate targets: the AMPERE study on staged accession scenarios for climate policy. Technol Forecast Soc Chang 90:24-44

Lamarque JF et al (2010) Historical (1850-2000) gridded anthropogenic and biomass burning emissions of reactive gases and aerosols: methodology and application. Atmos Chem Phys 10(15):7017-7039

Lelieveld J, Evans JS, Fnais M, Giannadaki D, Pozzer A (2015) The contribution of outdoor air pollution sources to premature mortality on a global scale. Nature 525(7569):367

Luderer $\mathrm{G}$ et al (2017) Assessment of wind and solar power in global low-carbon energy scenarios: an introduction. Energy Econ 64:542-551

Klaassen GA, Førsund FR, Amann M (1994) Emission trading in Europe with an exchange rate. Environ Resour Econ 4(4):305-330

Markandya A et al (2018) Health co-benefits from air pollution and mitigation costs of the Paris agreement: a modelling study. The Lancet Planetary Health 2(3):e126-e133

Masterman CJ, Viscusi WK (2018) The income elasticity of global values of a statistical life: stated preference evidence. Journal of Benefit-Cost Analysis 9(3):407-434

McCollum DL, Krey V, Riahi K, Kolp P, Grubler A, Makowski M, Nakicenovic N (2013) Climate policies can help resolve energy security and air pollution challenges. Clim Chang 119(2):479-494

Muller NZ, Mendelsohn R (2009) Efficient pollution regulation: getting the prices right. Am Econ Rev 99(5): 1714-1739

Muller NZ, Mendelsohn R, Nordhaus W (2011) Environmental accounting for pollution in the United States economy. Am Econ Rev 101(5):1649-1675

Nemet GF, Holloway T, Meier P (2010) Implications of incorporating air-quality co-benefits into climate change policymaking. Environ Res Lett 5(1):014007

Ou Y, Shi W, Smith SJ, Ledna CM, West JJ, Nolte CG, Loughlin DH (2018) Estimating environmental cobenefits of US low-carbon pathways using an integrated assessment model with state-level resolution. Appl Energy 216:482-493

Parry I, Veung C, Heine D (2015) How much carbon pricing is in countries' own interests? The critical role of cobenefits. Clim Chang Econ 6(04):1550019

Peng W, Yang J, Wagner F, Mauzerall DL (2017a) Substantial air quality and climate co-benefits achievable now with sectoral mitigation strategies in China. Sci Total Environ 598:1076-1084

Peng W, Yuan J, Zhao Y, Lin M, Zhang Q, Victor DG, Mauzerall DL (2017b) Air quality and climate benefits of long-distance electricity transmission in China. Environ Res Lett 12(6):064012

Rachel M. Hoesly, Steven J. Smith, Leyang Feng, Zbigniew Klimont, Greet Janssens-Maenhout, Tyler Pitkanen, Jonathan J. Seibert, Linh Vu, Robert J. Andres, Ryan M. Bolt, Tami C. Bond, Laura Dawidowski, Nazar Kholod, June-ichi Kurokawa, Meng Li, Liang Liu, Zifeng Lu, Maria Cecilia P. Moura, Patrick R. O'Rourke, Qiang Zhang, (2018) Historical (1750-2014) anthropogenic emissions of reactive gases and aerosols from the Community Emissions Data System (CEDS). Geoscientific Model Development 11 (1):369-408

Rao S et al (2016) A multi-model assessment of the co-benefits of climate mitigation for global air quality. Environ Res Lett 11(12):124013-124024

Rauner S, Hilaire J, Kleina D, Strefler J, Luderer G (2019) Air quality co-benefits of ratcheting-up the NDCs. Change, Climatic (in review)

Riahi K et al (2017) The shared socioeconomic pathways and their energy, land use, and greenhouse gas emissions implications: an overview. Glob Environ Chang 42:153-168

Shindell DT (2015) The social cost of atmospheric release. Clim Chang 130(2):313-326

Silva RA, Adelman Z, Fry MM, West JJ (2016) The impact of individual anthropogenic emissions sectors on the global burden of human mortality due to ambient air pollution. Environ Health Perspect 124(11):1776-1784

Smith SJ et al (2019) Impact of methane and black carbon mitigation on forcing and temperature: a multi-model scenario analysis. Clim Chang (in review)

Stanaway JD et al (2018) Global, regional, and national comparative risk assessment of 84 behavioural, environmental and occupational, and metabolic risks or clusters of risks for 195 countries and territories, 1990-2017: a systematic analysis for the Global Burden of Disease Study 2017. Lancet 392(10159):1923-1994

Tavoni $\mathrm{M}$ et al (2015) Post-2020 climate agreements in the major economies assessed in the light of global models. Nat Clim Chang 5(2):119-126 
Thompson TM, Rausch S, Saari RK, Selin NE (2014) A systems approach to evaluating the air quality cobenefits of US carbon policies. Nat Clim Chang 4(10):917

UNEP (2018). Air pollution in Asia and the Pacific: science-based solutions

Unger N, Bond TC, Wang JS, Koch DM, Menon S, Shindell DT, Bauer S (2010) Attribution of climate forcing to economic sectors. Proc Natl Acad Sci 107(8):3382-3387

Van Dingenen R, Crippa M, Maenhout G, Guizzardi D, Dentener F (2018a) Global trends of methane emissions and their impacts on ozone concentrations, JRC Science for Policy Report, EUR 29394 EN, Publications Office of the European Union, Luxembourg

Van Dingenen R et al (2018b) TM5-FASST: a global atmospheric source-receptor model for rapid impact analysis of emission changes on air quality and short-lived climate pollutants. Atmos Chem \& Phys 18: 16173-16211

Van Vuuren DP et al (2011) The representative concentration pathways: an overview. Clim Chang 109(1-2):5

van Zelm R, Preiss P, van Goethem T, Van Dingenen R, Huijbregts M (2016) Regionalized life cycle impact assessment of air pollution on the global scale: damage to human health and vegetation. Atmos Environ 134: 129-137

Vandyck T et al (2018) Air quality co-benefits for human health and agriculture counterbalance costs to meet Paris Agreement pledges. Nat Commun 9(1):4939

von Stechow $\mathrm{C}$ et al (2016) $2^{\circ} \mathrm{C}$ and SDGs: united they stand, divided they fall? Environ Res Lett 11(3):034022

West JJ, Fiore AM, Horowitz LW (2012) Scenarios of methane emission reductions to 2030: abatement costs and co-benefits to ozone air quality and human mortality. Clim Chang 114(3-4):441-461

West JJ et al (2013) Co-benefits of mitigating global greenhouse gas emissions for future air quality and human health. Nat Clim Chang 3(10):885

Zhang Y, Smith SJ, Bowden JH, Adelman Z, West JJ (2017) Co-benefits of global, domestic, and sectoral greenhouse gas mitigation for US air quality and human health in 2050. Environ Res Lett 12(11):114033

Publisher's note Springer Nature remains neutral with regard to jurisdictional claims in published maps and institutional affiliations. 